\title{
AUMENTO DA VIDA ÚTIL DA ÁREA DE DISPOSIÇÃO DE RESÍDUO DE BAUXITA*
}

\author{
Roberto Seno Júnior ${ }^{1}$ \\ Rodrigo Aparecido Moreno² \\ Thiago Teixeira Franco 3 \\ Alexandre Rezende de Freitas ${ }^{4}$ \\ Eduardo Marchioni Escobar ${ }^{5}$
}

\section{Resumo}

O Processo Bayer para a produção de Óxido de Alumínio consiste em dissolver o alumínio presente na minério de alumínio (Bauxita) com soda cáustica à quente. Os resíduos insolúveis são separados por decantação e filtração. Após lavagem deste resíduo para a recuperação da alumina e soda cáustica ele é transferido para áreas de disposição. A Companhia Brasileira de Alumínio produz 420 mil toneladas de alumínio por ano gerando cerca de 2.400 toneladas de resíduo de bauxita por dia. Este resíduo é transferido para uma área de disposição, denominada Palmital, com capacidade de estocagem para mais 9 anos. Atualmente, o Palmital contém cerca de 2 milhões de metros cúbicos de água sobrenadante. Esta água contém alumínio e soda cáustica dissolvidos que podem ser reutilizados na Refinaria de Alumina. Este trabalho estuda formas de reutilização desta água sobrenadante visando aumentar a vida útil do Palmital, ou seja, aumentar o volume disponível para disposição de resíduo de bauxita.

Palavras-chave: Resíduo de bauxita; Refinaria alumina; Área de disposição de Resíduo; Bauxita; Alumina; Óxido de alumínio; Lama vermelha.

\section{INCREASING THE CAPACITY OF BAUXITE RESIDUE DISPOSAL AREA Abstract}

The Bayer Process for producing aluminum oxide is to dissolve the aluminum present in the aluminum ore (Bauxite) with hot caustic soda. The insoluble residue is separated by decantation and filtration. After residue washing for alumina and caustic recovery, the washed residue is transferred to the disposal area. The Companhia Brasileira de Alumínio (CBA) produces 420,000 tonnes of aluminum per year, generating about 2,400 tons of bauxite residue per day. This residue is pumped to a disposal area, called Palmital, with storage capacity for next 9 years. Currently, Palmital contains about 2 million cubic meters of supernatant water. This water contains dissolved aluminum and caustic soda that can be reused in Alumina Refinery. This paper studies ways to reuse this supernatant water to increase the available volume for bauxite residue disposal

Keywords: Bauxite residue; Alumina refinary; Mud lake; Bauxite; Alumina; Aluminum oxide; Red mud.

1 Engenheiro Químico, Gerente de Tecnologia de Bauxita e Alumina, Tecnologia da Alumina, Votorantim Metais - Cia. Brasileira de Alumínio, Alumínio, São Paulo, Brasil.

2 Bacharelado em Química, Consultor de Processo I, Tecnologia de Bauxita e Alumina, Votorantim Metais - Cia. Brasileira de Alumínio, Alumínio, São Paulo, Brasil.

3 Engenheiro Químico, Engenheiro de Processos, Tecnologia de Bauxita e Alumina, Votorantim Metais - Cia. Brasileira de Alumínio, Alumínio, São Paulo, Brasil.

4 Engenheiro Químico, Engenheiro de P\&D, Tecnologia de Bauxita e Alumina, Votorantim Metais Cia. Brasileira de Alumínio, Alumínio, São Paulo, Brasil.

5 Química, Mestre, Consultor de Processo II, Tecnologia de Bauxita e Alumina, Votorantim Metais Cia. Brasileira de Alumínio, Alumínio, São Paulo, Brasil.

\footnotetext{
* Contribuição técnica ao $35^{\circ}$ Seminário de Balanços Energéticos Globais e Utilidades e $29^{\circ}$ Encontro de Produtores e Consumidores de Gases Industriais, 13 a 15 de agosto de 2014, São Paulo, SP, Brasil.
} 


\section{INTRODUÇÃO}

A Companhia Brasileira de Alumínio (CBA), na etapa de processamento de bauxita para obtenção de óxido de alumínio (alumina), possui uma barragem para disposição dos resíduos do processo, denominada Palmital (Figura 1). Atualmente, todas as plantas do mundo de refinaria de alumina possuem áreas para disposição de seus resíduos, sendo a maior parte em disposição por decantação dos sólidos. O principal material disposto na barragem é o resíduo de bauxita.

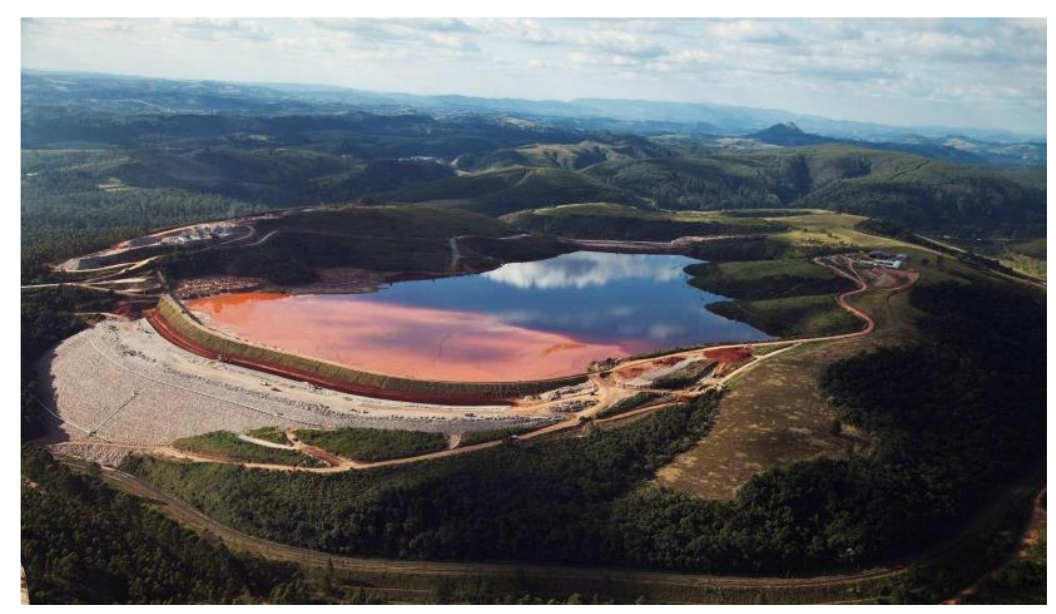

Figura 1 - Palmital

A Refinaria produz 5.000 toneladas por dia de resíduo de bauxita com $50 \%$ de concentração de sólidos. Neste ritmo, a barragem, que já recebeu um alteamento final em 2008, terá seu volume útil esgotado em 2023. A partir dessa data, será necessário desenvolver uma alternativa para disposição do material. A construção de outra barragem, além de ter um custo muito alto e gerar movimentação de veículos para uma área distante da fábrica, implica ainda, na disposição dos resíduos com teor cáustico em novas áreas ainda não utilizadas.

A solução proposta para estender a vida útil da barragem atual e reduzir os riscos ambientais é alterar a forma de disposição do resíduo, do atual "Wet Disposal" (baixa concentração de sólidos) para o "Dry Disposal", com $75 \%$ de concentração de sólidos. Para a disposição de forma sólida é necessário a utilização de filtro prensa.

Essa modificação também possibilitará a recuperação da soda cáustica presente na fração líquida filtrada e um aumento de pelo menos 20 anos na vida útil da barragem. No entanto, para que esta opção seja realizada, é necessária a redução da quantidade do líquido sobrenadante da barragem.

Ao longo dos anos, ocorreu a decantação da fração sólida no fundo da barragem e o líquido sobrenadante, atualmente com cerca de $2.000 .000 \mathrm{~m}^{3}$, contém soda cáustica e alumina dissolvidas e concentração de sólidos desprezível. Essa fração líquida deve ser retirada para viabilizar a disposição do resíduo de bauxita na forma seca. Assim, o objetivo do projeto é o reaproveitamento da água contida na barragem para aumentar a vida útil da barragem evitando também a captação

\footnotetext{
* Contribuição técnica ao $35^{\circ}$ Seminário de Balanços Energéticos Globais e Utilidades e $29^{\circ}$ Encontro de Produtores e Consumidores de Gases Industriais, 13 a 15 de agosto de 2014, São Paulo, SP, Brasil.
} 


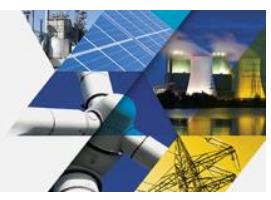

\section{MATERIAIS E MÉTODOS}

\section{1 "Dry Disposal"}

A mudança na forma de disposição do resíduo de bauxita para a técnica "Dry Disposal" implica na utilização de um filtro prensa para gerar o resíduo com umidade adequada, $25 \%$, para facilitar o seu manuseio e disposição. Um teste piloto foi conduzido para avaliar a eficácia do Filtro Prensa na redução da umidade do resíduo e outros parâmetros para a disposição.

\subsubsection{Filtro piloto}

Um teste piloto com Filtro Prensa (Figura 2) foi executado para avaliar a desempenho do equipamento e suas especificações para dimensionamento e para produzir resíduo filtrado para avaliação geotécnica. Este teste foi realizado em outubro de 2012.

Alimentou-se o filtro prensa com a suspensão de resíduo de bauxita na forma como ela é lançada na área de disposição e foram produzidos 500 quilos do resíduo filtrado.

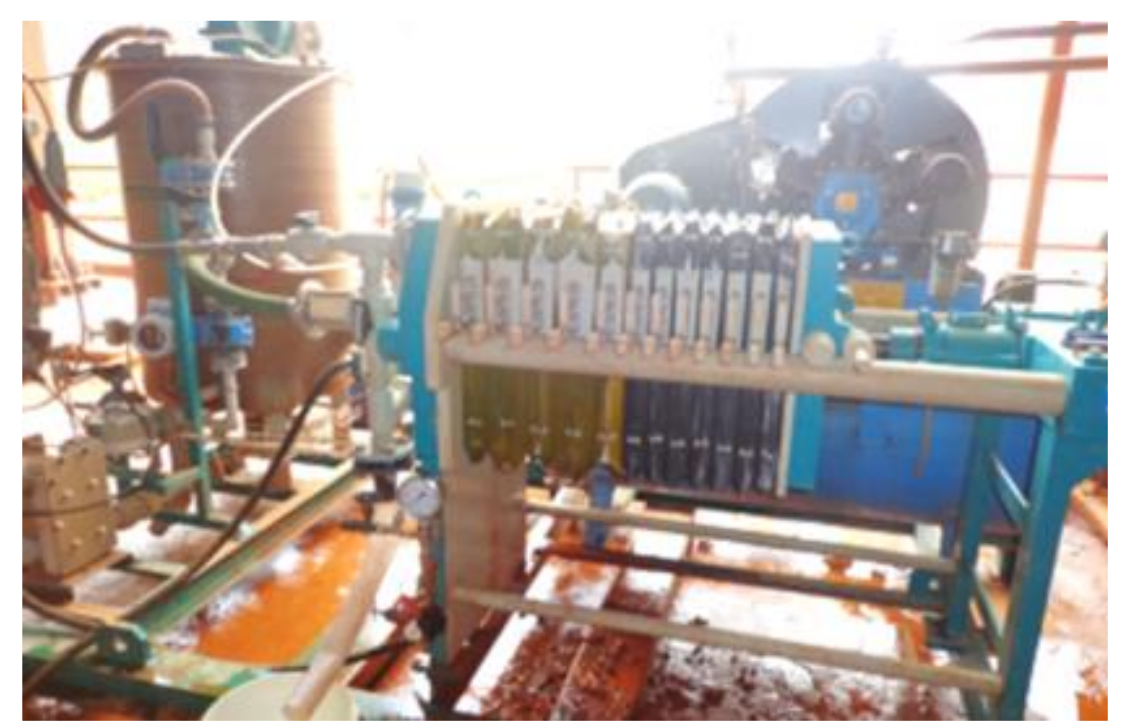

Figura 2 - Filtro Prensa

O resultado foi a separação do resíduo em duas frações. A torta do filtro (Figura 3) que é o resíduo final, compacto e com alta concentração de sólidos, (média 75\%) e o filtrado (Figura 4) com uma concentração de soda cáustica e alumina que permita 0 reaproveitamento na refinaria reduzindo o consumo de soda na planta.

O teste comprovou a redução no volume de resíduo em $25 \%$, a redução do volume de líquidos no resíduo em $42 \%$ e o aumento da recuperação de soda cáustica em $80 \%$. A soda cáustica é, hoje, o terceiro maior custo da refinaria da CBA. Além disso, trata-se de um volume líquido com teor cáustico que não será disposto na barragem, reduzindo o passivo ambiental da empresa. A comparação visual entre o resíduo atual e o resíduo obtido com o filtro prensa pode ser vista na Figura 5. 

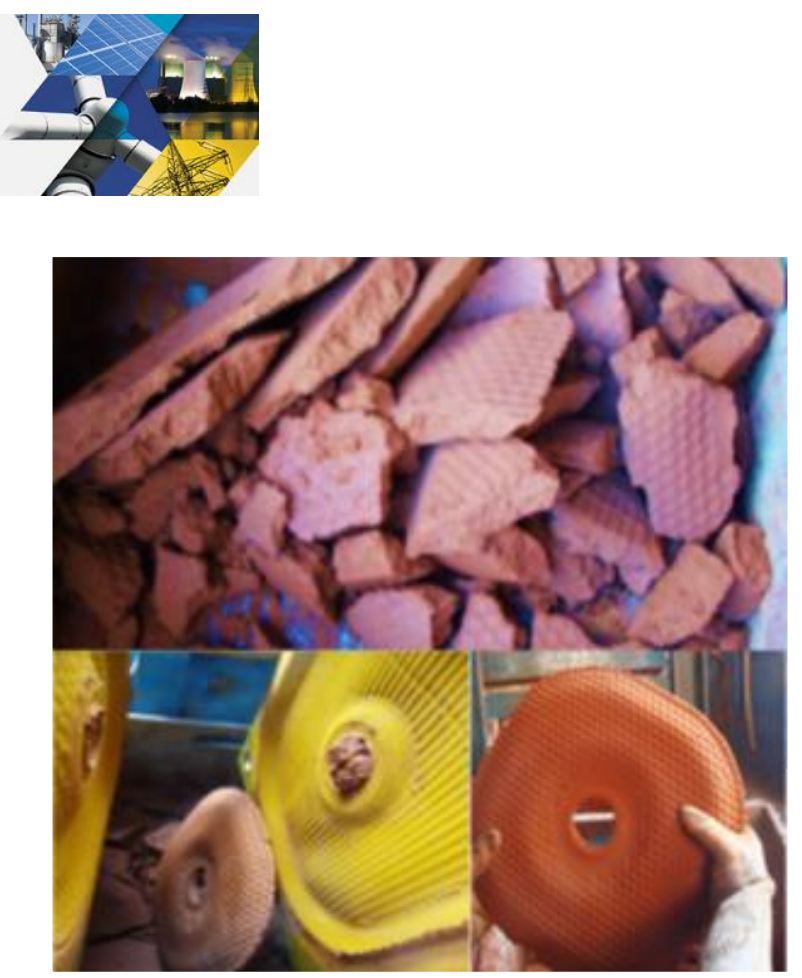

Figura 3 - Torta do filtro produzida no teste piloto

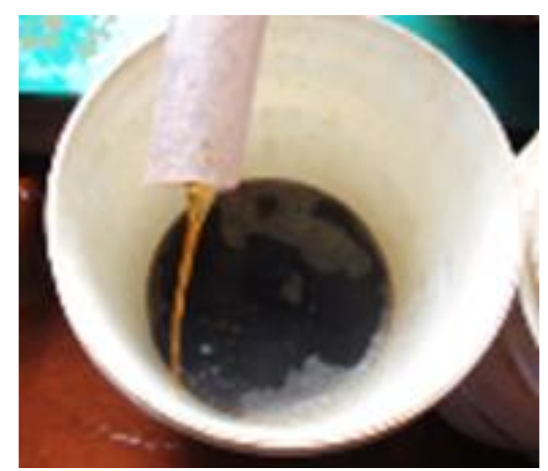

Figura 4- Licor cáustico recuperado no filtrado do teste piloto

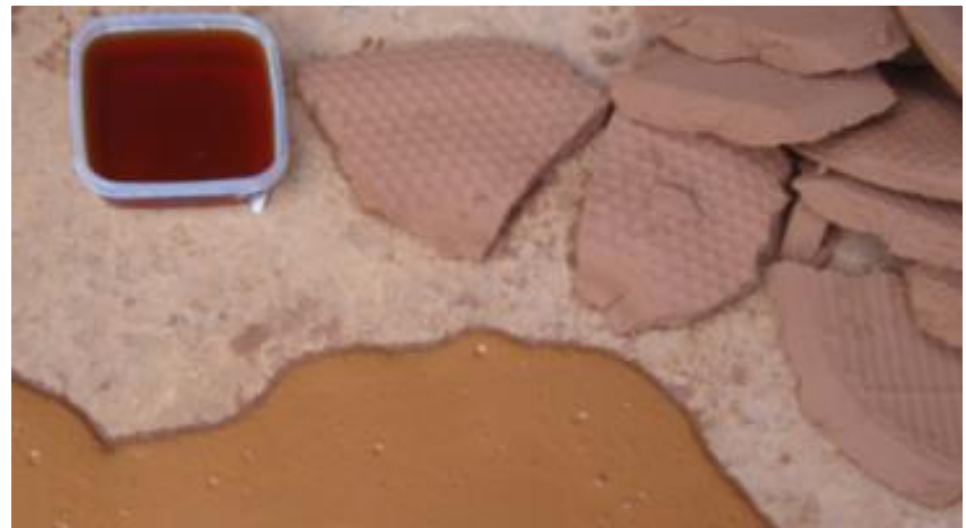

Figura 5 - Comparação entre os resíduos de disposição úmida e seca

\subsubsection{Teste de disposição}

Após a produção deste resíduo compacto, foi necessária determina parâmetros para planejar a forma de disposição como facilidade para o manuseio, ângulo de repouso (Figura 6), densidade de empilhamento para avaliar a compressão natural do resíduo e caracterização geotécnica.

\footnotetext{
* Contribuição técnica ao $35^{\circ}$ Seminário de Balanços Energéticos Globais e Utilidades e $29^{\circ}$ Encontro de Produtores e Consumidores de Gases Industriais, 13 a 15 de agosto de 2014, São Paulo, SP, Brasil.
} 

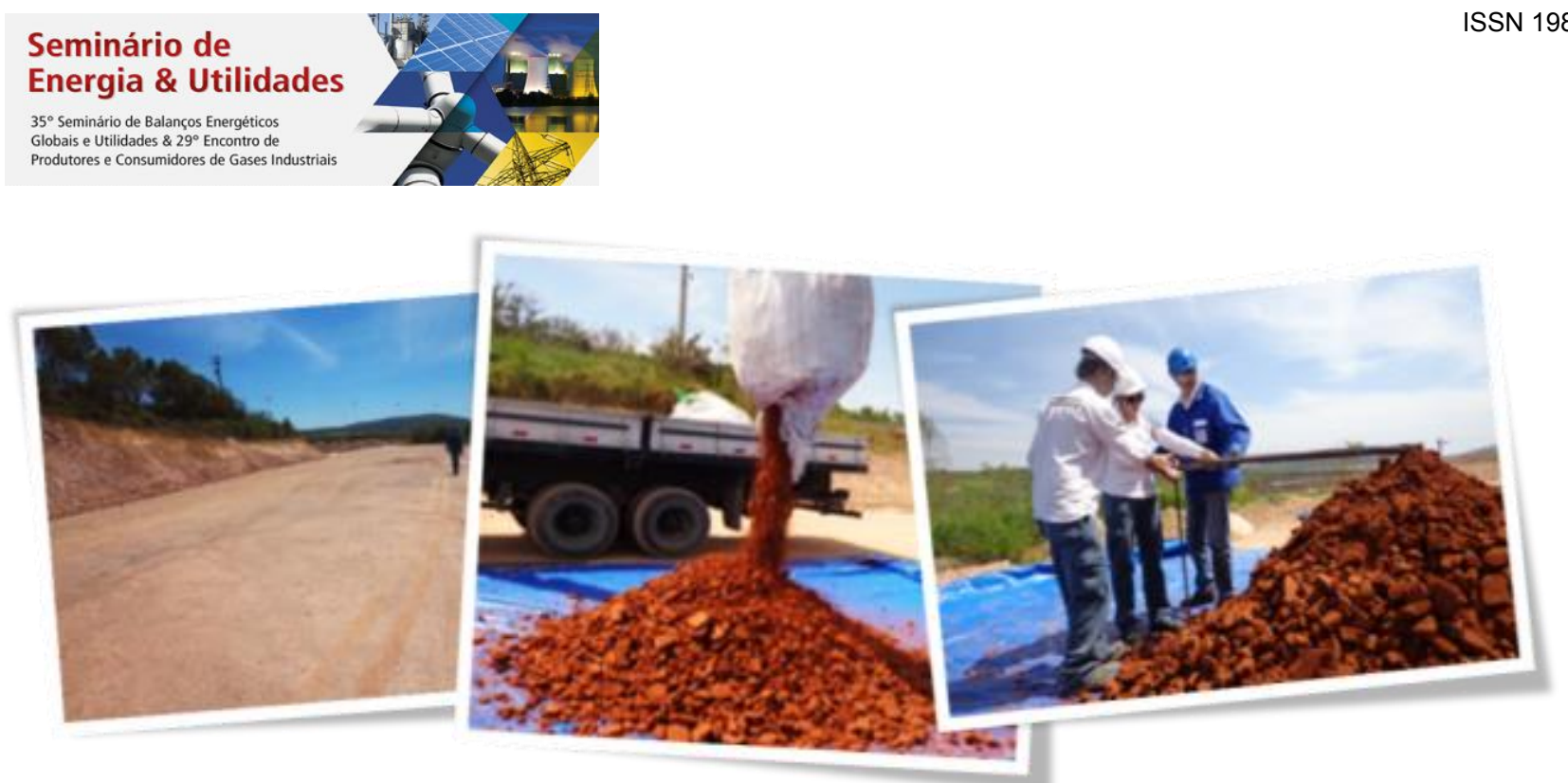

Figura 6 - Área e teste de disposição de resíduo do filtro prensa

Adicionalmente, também foi realizado um teste de compactação (Figura 7) utilizandose uma vala onde foi depositado o resíduo e avaliando-se a sua compactação através de passagens sucessivas de uma retroescavadeira sobre o material. Os resultados de compactação comprovaram a viabilidade do projeto.

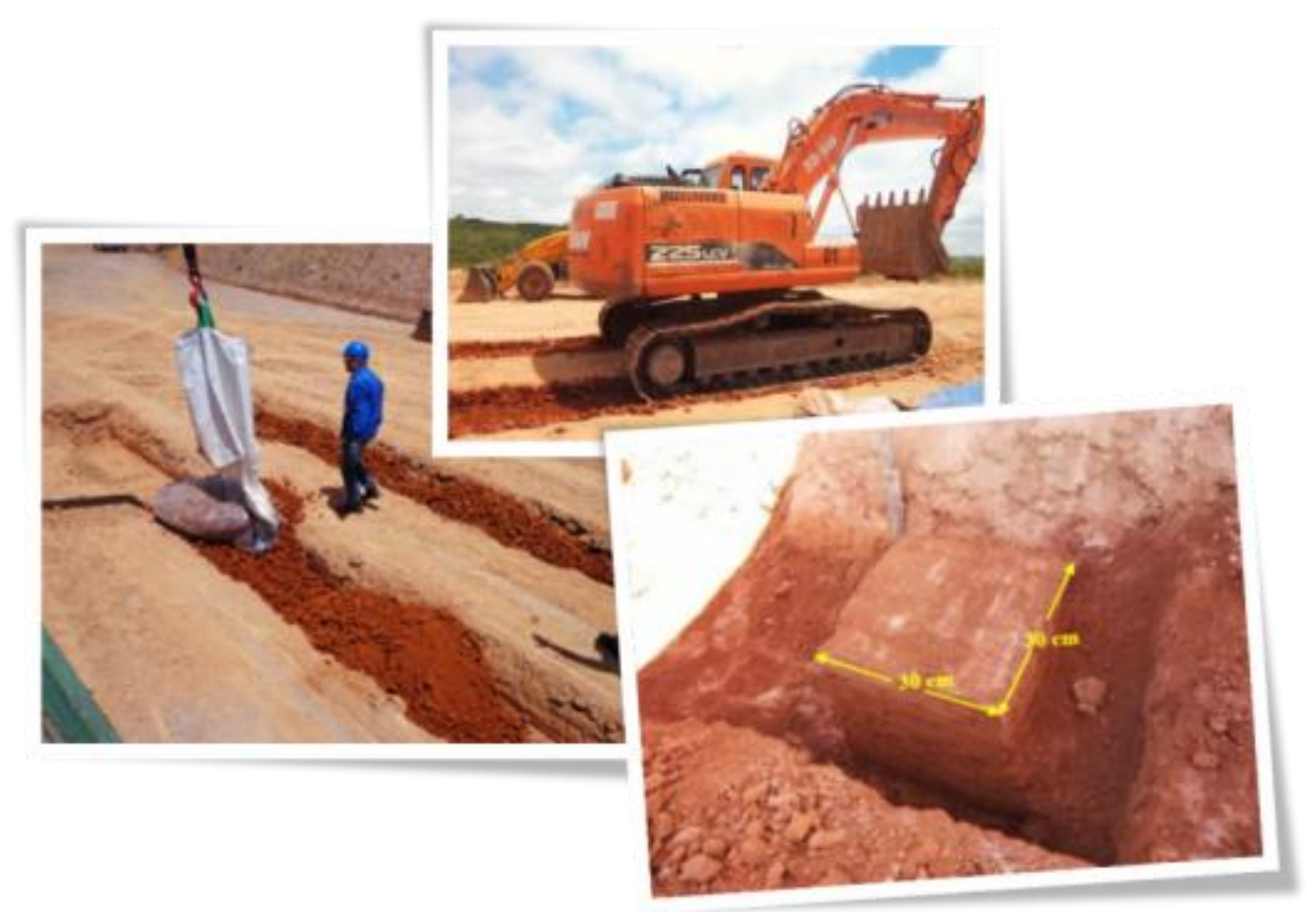

Figura 7 - Compactação extra, realizada passando uma escavadeira oito vezes sobre o trecho preenchido com resíduo.

Com os dados obtidos elaborou-se um novo projeto de disposição do resíduo de bauxita (Figura 8), utilizando-se toda área disponível no Palmital. Este projeto permite aumentar a vida útil do Palmital em 25 anos. 


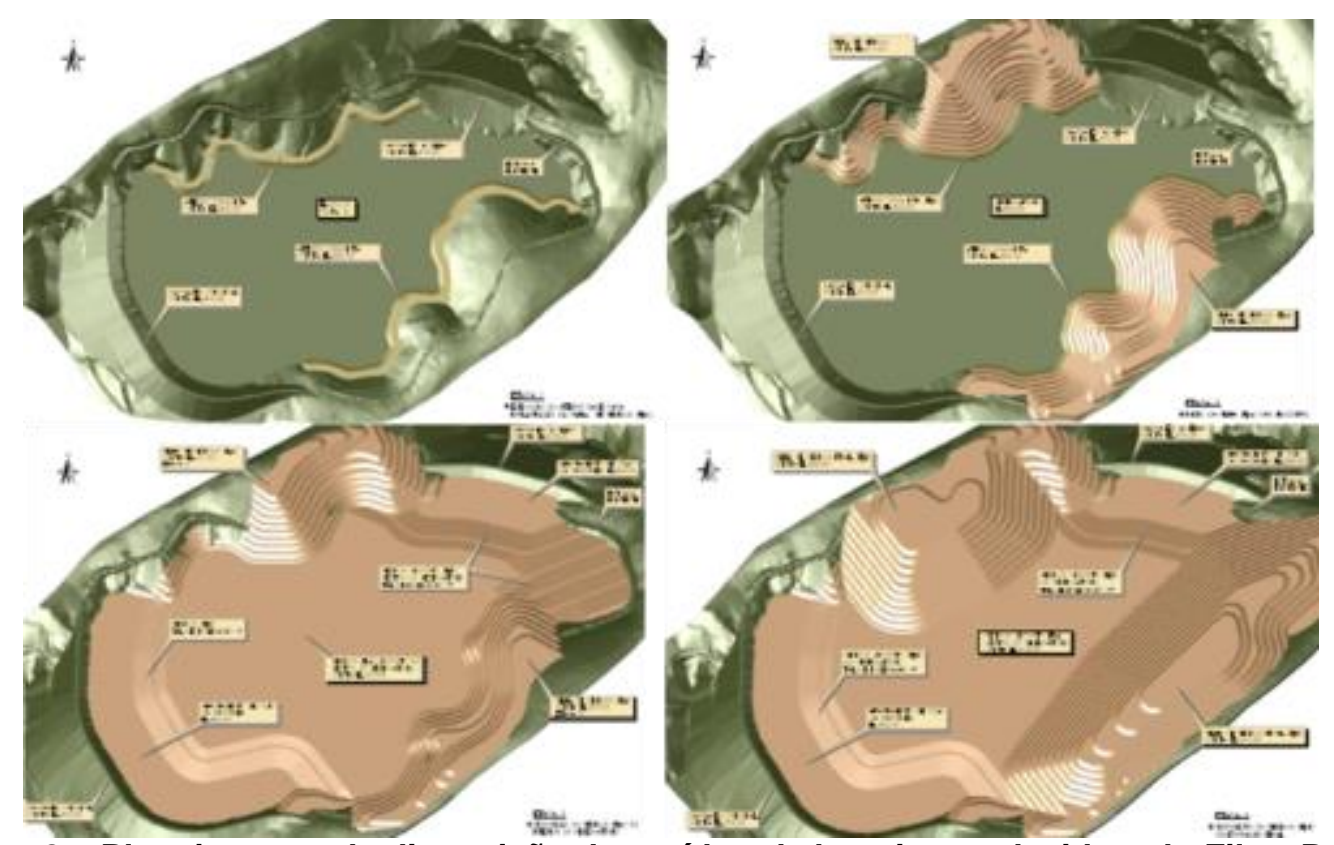

Figura 8 - Planejamento da disposição do resíduo de bauxita produzido pelo Filtro Prensa

Esta alteração na forma de disposição do resíduo de bauxita permite recuperar soda cáustica e alumina com valor na ordem de $\mathrm{R} \$ 24$ milhões ao ano, além da postergar 25 anos o investimento de $\mathrm{R} \$ 300$ milhões na construção de uma nova barragem.

\section{RESULTADOS E DISCUSSÃO}

\subsection{Utilização da Água do Palmital}

Uma batimetria realizada em 2012 indicou a existência de $2.000 .000 \mathrm{~m}^{3}$ de água sobrenadante do Palmital, que precisa ser retirada do lago para viabilizar a disposição do resíduo produzido com o filtro prensa. Inicialmente, foi realizada uma caracterização dessa água que indicou concentrações baixas de fluoreto de sódio, cloreto de sódio, sulfato de sódio e oxalato de sódio na faixa entre 0,4 e 0,6 g/L. A água também contém $30 \mathrm{~g} / \mathrm{L}$ de Total Alcalino (TA), que é a soma das concentrações de hidróxido de sódio $(\mathrm{NaOH})$ e carbonato de sódio, e $8 \mathrm{~g} / \mathrm{L}$ de alumina $\left(\mathrm{Al}_{2} \mathrm{O}_{3}\right)$. $\mathrm{O}$ valor destes produtos contidos na solução sobrenadante do Palmital é, aproximadamente, $\mathrm{R} \$ 57$ milhões.

A partir desta análise, procurou-se identificar opções para utilização desta água no próprio processo produtivo. As duas melhores alternativas foram substituir o condensado utilizado nos processos da hidratação da cal e a água industrial utilizada no processo de diluição de floculante.

\subsubsection{Utilização da água do palmital na preparação do floculante}

A fim de verificar a eficiência da água do Palmital na abertura de floculante, testes de substituição da Água Industrial por Água do Palmital foram executados na preparação do floculante e medindo-se a velocidade de sedimentação dos sólidos nos espessadores. A preparação do floculante é feita em duas diluições, A primeira a $1 \%$ e a segunda a $0,3 \%$. O resultado final, exibido na Figura 9, mostra que a velocidade de decantação do resíduo melhora significativamente quando a água industrial é utilizada na primeira diluição do floculante e a água do Palmital na segunda diluição. 


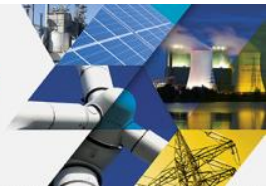

Estes números validam a substituição da Água Industrial pela Água do Palmital na segunda diluição permitindo um aumento na eficácia do floculante.

\section{Settling rate $\mathrm{mt} / \mathrm{hours}$}

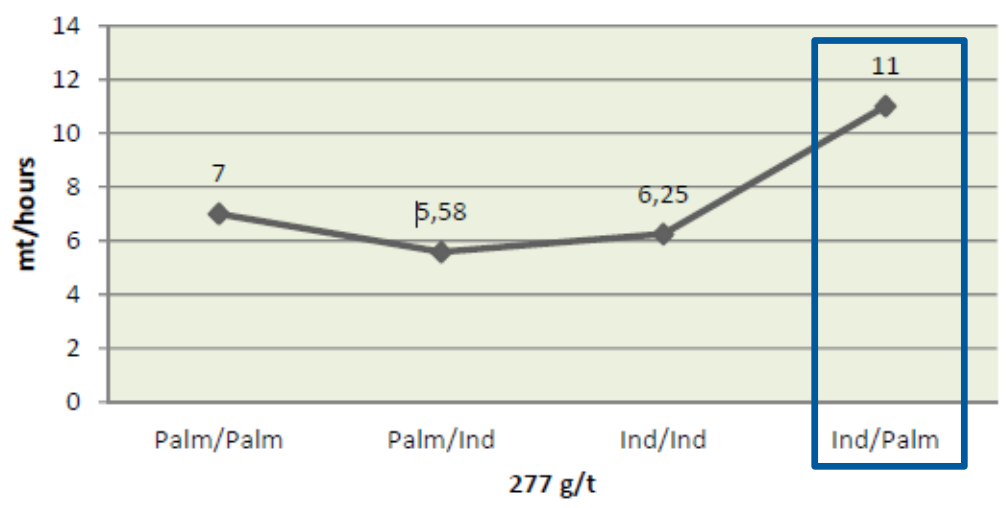

Figura 9 - Velocidade de Decantação de Sólidos

\subsubsection{Utilização da água do palmital na hidratação da cal}

Para a substituição do condensado na hidratação da cal pela água do Palmital, que contém impurezas [1-4], foi necessário avaliar o limite de concentração de oxalato de sódio aceitável na solução de aluminato de sódio do processo sem comprometer a produção e a qualidade do óxido de alumínio.

\subsubsection{Determinação do "break point" de oxalato de sódio na solução de aluminato de sódio}

O "Break Point" é a concentração máxima de Oxalato de Sódio que permanece solúvel na solução de aluminato de sódio nas condições do processo.

O teste consiste em avaliar o impacto das impurezas da água do Palmital no "Break Point" de Oxalato de Sódio.

Em um conjunto de frascos de polipropileno foram adicionadas alíquotas crescentes de Oxalato de Sódio numa solução de aluminato de sódio do processo, previamente evaporada para manter a Alcalinidade Total Final em $290 \mathrm{gNa}_{2} \mathrm{CO}_{3} / \mathrm{L}$. Água do Palmital concentrada por evaporação também foi adicionada para avaliar o efeito das impurezas na solução do processo. (Tabela 1). Após 2 horas a $70^{\circ} \mathrm{C}$, sob agitação constante em banho de água, foi determinada a concentração de $\mathrm{Na}_{2} \mathrm{C}_{2} \mathrm{O}_{4}$.

Tabela 1 - Teste de Break Point de Na2C2O4

\begin{tabular}{|c|c|c|c|c|c|c|c|c|}
\hline Amostras & $\begin{array}{l}\text { Vol. Inicial } \\
\text { (mL) }\end{array}$ & $\begin{array}{c}\text { Solução Oxalato } \\
24 \mathrm{gNa} 2 \mathrm{C} 2 \mathrm{O} 4 / \mathrm{L} \\
(\mathrm{mL})\end{array}$ & $\begin{array}{c}\text { Solução Oxalato } \\
30 \mathrm{gNa2C} 204 / \mathrm{L} \\
(\mathrm{mL})\end{array}$ & $\begin{array}{l}\text { Adição de } \\
\text { água (mL) }\end{array}$ & $\begin{array}{c}\text { Adição de } \\
\text { Palmital } \\
\text { Concentrado } 7 x \\
\text { (mL) }\end{array}$ & $\begin{array}{l}\text { Vol. Final } \\
\qquad(\mathrm{mL})\end{array}$ & $\begin{array}{l}\text { Conc.final } \\
\text { Oxalato } \\
\text { (gNa2C2O4/L) }\end{array}$ & $\begin{array}{l}\text { Conc.final TA } \\
\text { (gNa2CO3/L) }\end{array}$ \\
\hline Branco & 180 & 0 & 10 & 30 & 20 & 240 & 5,24 & 289 \\
\hline 1 & 180 & 5 & 10 & 25 & 20 & 240 & 5,74 & 289 \\
\hline 2 & 180 & 10 & 10 & 20 & 20 & 240 & 6,24 & 289 \\
\hline 3 & 180 & 15 & 10 & 15 & 20 & 240 & 6,74 & 289 \\
\hline 4 & 180 & 20 & 10 & 10 & 20 & 240 & 7,24 & 289 \\
\hline 5 & 180 & 25 & 10 & 5 & 20 & 240 & 7,74 & 289 \\
\hline 6 & 180 & 30 & 10 & 0 & 20 & 240 & 8,24 & 289 \\
\hline
\end{tabular}

Foi realizado um teste em branco, ou seja, sem a adição de Água do Palmital e outro com a adição de $20 \mathrm{~mL}$ de Água do Palmital concentrada 7:1. Com os resultados obtidos construiu-se o gráfico mostrado na Figura 10 que evidencia uma redução no "Break Point" do $\mathrm{Na}_{2} \mathrm{C}_{2} \mathrm{O}_{4}$ de 7,3 $\mathrm{gNa}_{2} \mathrm{C}_{2} \mathrm{O}_{4} / \mathrm{L}$ para 6,3 $\mathrm{gNa}_{2} \mathrm{C}_{2} \mathrm{O}_{4} / \mathrm{L}$. 


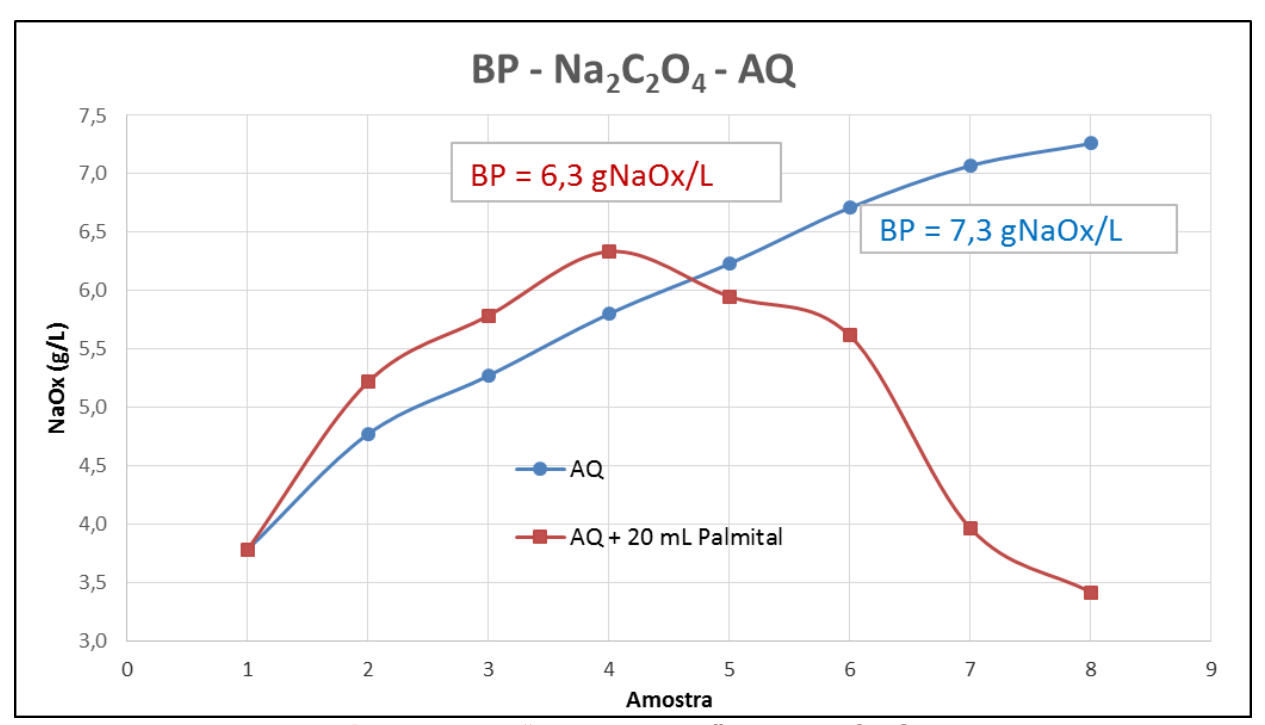

Figura 10 - "Break Point" de Na2C2O4

\subsubsection{Acompanhamento do teor de $\mathrm{Na}_{2} \mathrm{C}_{2} \mathrm{O}_{4}$ no processo}

Um monitoramento semanal das impurezas na solução de aluminato de sódio do processo é utilizado para controlar o fluxo de adição de água do Palmital (Figura 11).

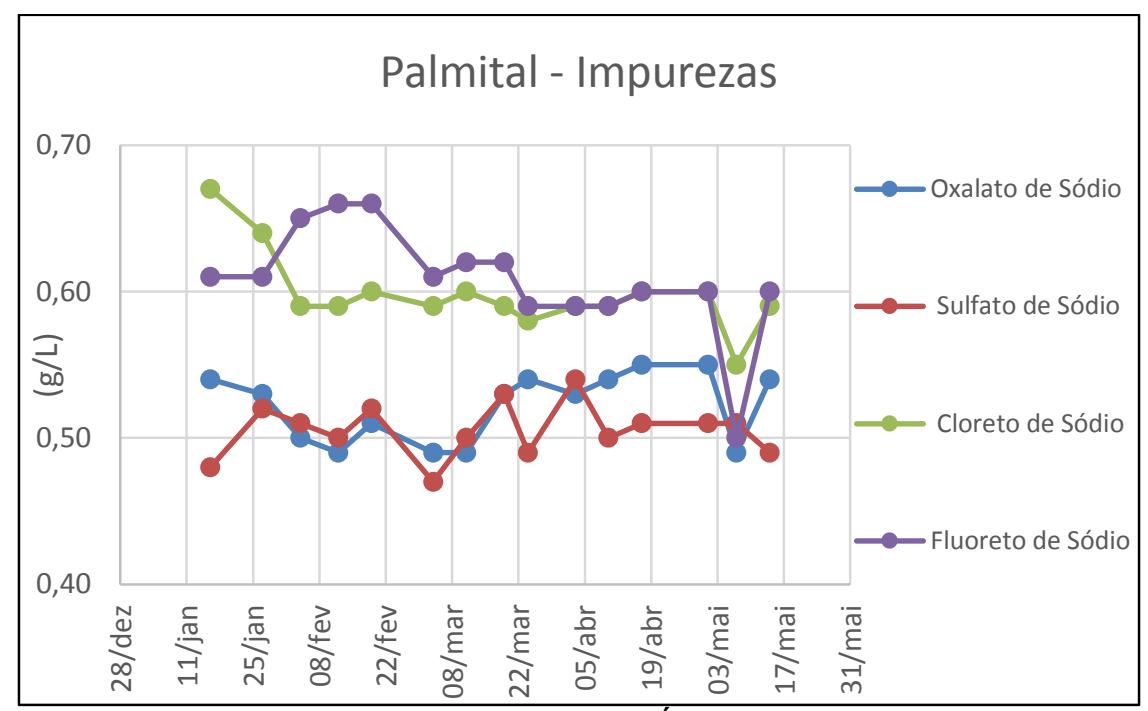

Figura 11 - Impurezas na Água do Palmital

\section{CONCLUSÃO}

4.1. Testes piloto comprovaram que com filtro prensa é possível produzir um resíduo de bauxita com $25 \%$ de umidade.

4.2. O método de disposição de resíduo de bauxita "Dry Disposal" permite, através do aumento da concentração de sólidos por unidade de volume e utilização das margens do depósito e aumentar, em 25 anos, a capacidade de estocagem do resíduo de bauxita.

4.3 A substituição da água industrial pela água do Palmital na segunda etapa de diluição do floculante do espessador é viável e propicia um aumento na velocidade de sedimentação dos sólidos.

4.4 O aumento de concentração das impurezas na solução de processo devido à adição de água do Palmital reduz a solubilidade do oxalato de sódio na solução de processo ("Break Point") e deve ser monitorada. 
4.5 Desde julho de 2013, quando iniciamos a de utilização de água do Palmital na Refinaria de Alumina, foram reutilizados cerca de 94 mil m3 de água, com valor aproximado de $R \$ 2,5$ milhões.

\section{Agradecimentos}

Agradeço às equipes de Tecnologia da Alumina, à da Engenharia de Processo da Alumina e à do Laboratório Químico o apoio e participação no desenvolvimento dos trabalhos ligados a este projeto.

\section{REFERÊNCIAS}

1 Chaplin N. Reaction of lime in sodium aluminate liquors. Essential Readings in Light Metals. 2013;1:202-209.

2 Rosemberg S, Wilson D, Heath C. Some aspects of calcium chemistry in bayer process. Essential Readings in Light Metals. 2013;1:210-216.

3 Young R. Essential Readings in Light Metals. 2013;1:217-227.

4 Roach G. Essential Readings in Light Metals. 2013;1:228-234. 